Portland State University

PDXScholar

\title{
The percentage consonants correct and intelligibility of normal, language delayed, and history of language delayed children
}

Randi Jartun

Portland State University

Follow this and additional works at: https://pdxscholar.library.pdx.edu/open_access_etds

Part of the Speech and Hearing Science Commons

Let us know how access to this document benefits you.

\section{Recommended Citation}

Jartun, Randi, "The percentage consonants correct and intelligibility of normal, language delayed, and history of language delayed children" (1992). Dissertations and Theses. Paper 4328.

https://doi.org/10.15760/etd.6212

This Thesis is brought to you for free and open access. It has been accepted for inclusion in Dissertations and Theses by an authorized administrator of PDXScholar. Please contact us if we can make this document more accessible: pdxscholar@pdx.edu. 
AN ABSTRACT OF THE THESIS OF Randi Jartun for the Master of Science in speech Communication: Speech and Hearing Science presented November 4, 1992 .

Title: The Percentage consonants Correct and Intelligibility of Normal, Language Delayed, and History of Language Delayed Children

APPROVED BY MEMBERS OF THE THESIS COMMITTEE:
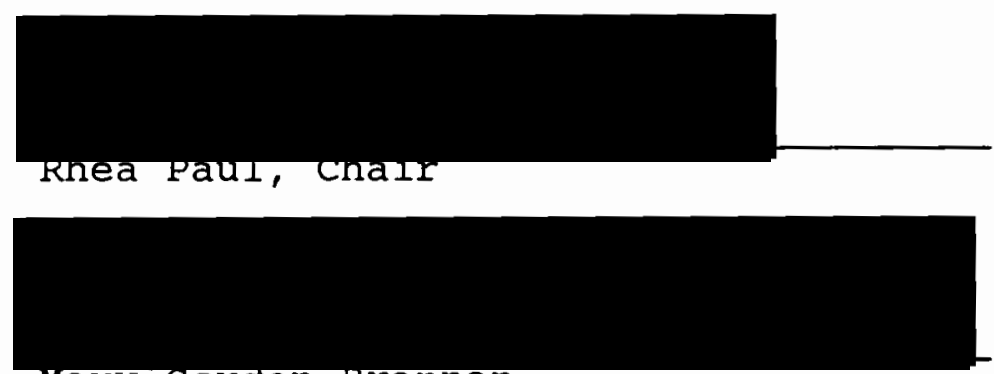

Mary Goragn-Brannan

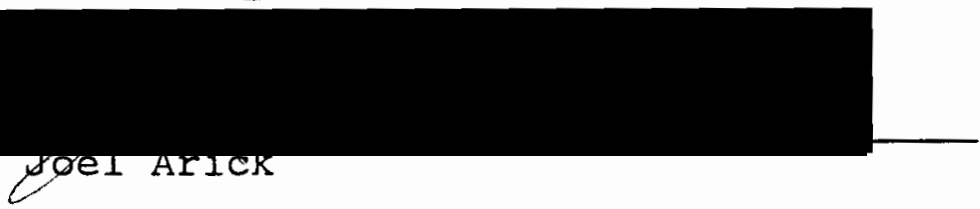

Highiy unintelligible children may mistakenly be assumed to have difficulty only with the misarticulation of consonants. Expressive language concerns may be ignored while the primary focus of intervention becomes the correction of misarticulated speech. Questions have arisen regarding the possibility of both speech and expressive language difficulties contributing to unintelligibility. Shriberg and Kwiatkowski (1982) developed an ordinal means 
of rating severity of involvement. One of the constructs of the severity scale was intelligibility. The metric percentage consonants correct (PCC) was developed to identify severity of involvement of disorders of phonology.

The purpose of the present study was to examine intelligibility and determine a possible interrelatedness of speech and expressive language development. Two-year-old subjects of a longitudinal study were initially placed into one of two groups based on results of a parent report, the Language Development Survey (Rescorla, 1989). Children placed in the normal group produced more than 50 words at 20-34 months. Children placed in the group labeled "late-talkers" produced less than 50 words at 20-34 months. At 4 years of age, the children were divided into three groups based on scores from Lee's (1974) Developmental Sentence score (DSS). The normal subgroup consisted of children diagnosed as normal at intake and whose scores on the DSS were at or above the 10th percentile. A second group, the history of expressive language delay group, consisted of children considered "late-talkers" at intake and whose scores were above the loth percentile on the DSS. A third group, the expressive language delay group, was formed which consisted of children considered "late-talkers" at intake and whose scores were below the loth percentile on the DSS.

Speech-language samples from the 4-year evaluation were phonetically transcribed and analyzed using the 
Programs to Examine Phonetic and Phonologic Evaluation Records (PEPPER), a computer program created by Shriberg (1986). A PCC value was determined for each speech-language sample.

The following specific questions were addressed:

1. Is there a significant difference in the PCC produced by children who are normal, expressive language delayed, or have a history of expressive language delay?

2. Is there a significant difference in subjective ratings of intelligibility among these three groups?

3. Does the PCC severity rating correlate with subjective ratings of intelligibility?

The data were analyzed to determine if a significant difference existed on the PCC values produced by the language diagnostic groups. A one-way analysis of variance (ANOVA) found a significant difference $(\underline{F}=7.06$ at the .05 level of significance). Results of a Tukey test indicated that the normal group received significantly better PCC values than both the history of expressive language delay group and the expressive language delay group. No significant difference was found between the PCC values of the expressive language delay group and the history of expressive language delay group.

A chi-square analysis was conducted to establish the extent of association among subjective ratings of intelligibility and the various groups. Normal language group ratings were most often associated with "good" 
subjective ratings while the expressive language delay group was most often associated with the "poor" group. The history of expressive language delay group had ratings almost evenly distributed between the combined "fair" and "poor" group and the "good" group.

A Spearman Rank order correlation coefficient was performed to determine the relationship between PCC severity rating and subjective ratings of intelligibility. A moderate yet significant difference $(p<.05)$ was found. 


\section{THE PERCENTAGE CONSONANTS CORRECT \\ AND INTELLIGIBILITY OF \\ NORMAL, LANGUAGE DELAYED, AND \\ HISTORY OF LANGUAGE DELAYED CHILDREN}

by

RANDI JARTUN

A thesis submitted in partial fulfillment of the requirements for the degree of

MASTER OF SCIENCE
in
SPEECH COMMUNICATION: SPEECH AND HEARING SCIENCE

Portland State University

1992 


\section{TO THE OFFICE OF GRADUATE STUDIES:}

The members of the committee approve the thesis of Randi Jartun presented November 4, 1992 .
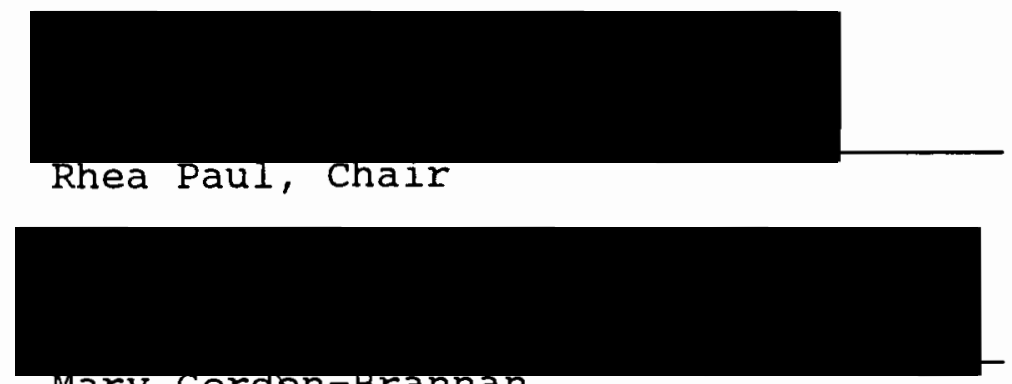

Mary Gordqn-Brannan

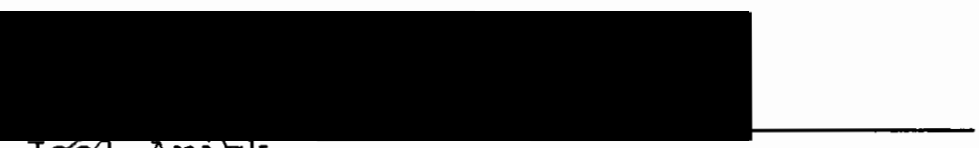

Jø1 ArIEK

\section{APPROVED :}

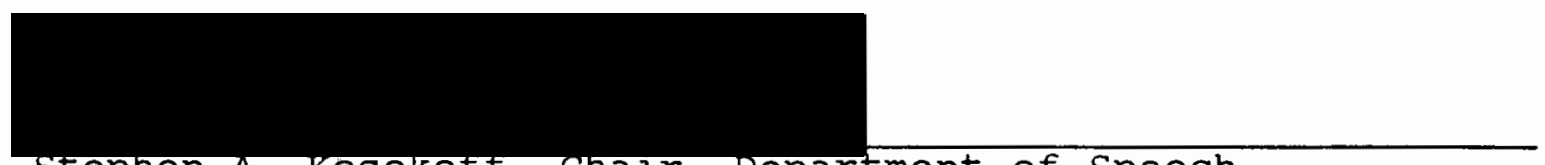

stephen A. Kosokolt, chalr, Department of Speech Communication

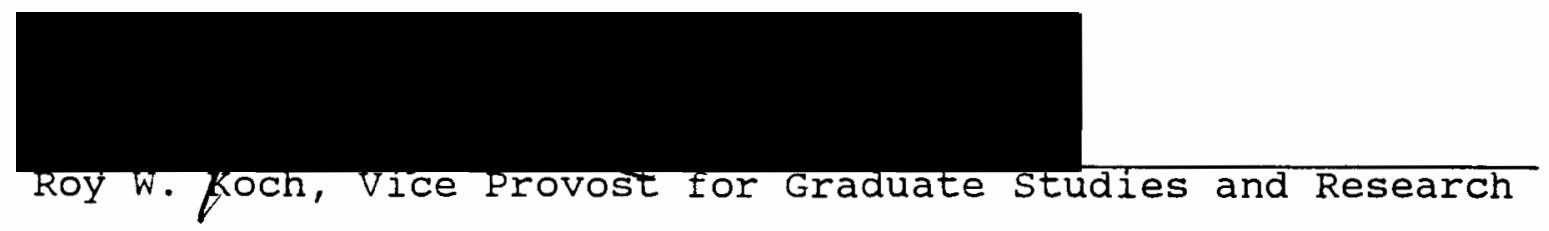


ACKNOWLEDGEMENTS

I would like to extend my sincere appreciation to my thesis advisor, Rhea Paul, Ph.D. for her advice and support. It was a privilege to work on the Portland Language Development study.

Thank you to other committee members Mary Gordon-Brannan and Joel Arick for their helpful comments and guidance.

Thanks also to Mark Greene, my statistical advisor, who put up with an incredibly nonstatistically minded individual.

In addition, thank you to my friends who encouraged me and forgave my frequent disappearances during grad school.

Finally, I dedicate this work to three people who have influenced my life in very unique ways. First to my mother, Marcia Jartun, who has supported me in every way possible throughout this endeavor. Her creative powers and quiet devotion to others is a constant source of pride and inspiration. Next, to the memory of my father, kjell Jartun, who always encouraged me to do my best, cherish my Norwegian heritage, and to put things back where they belong. I am still working on the last one, Dad. And finally to the memory of my precious daughter, Rachael, I quote an unknown author whose words have helped me through 
some dark hours. "What we have once enjoyed we can never 1ose. All that we love deeply becomes a part of us." I love you all. 
TABLE OF CONTENTS

PAGE

ACKNOWLEDGEMENTS

LIST OF TABLES

CHAPTER

I

INTRODUCTION AND STATEMENT OF PURPOSE • •

Introduction . . . . . . . . . . .

Statement of Purpose . . . . . . . 3

Definition of Terms . . . . . . . 5

II REVIEW OF THE LITERATURE.$\cdot \cdot$. . . . •

Normal Speech Development . . . . .

Interactions Between Speech and

Language Development in

Language Disordered Children . .

Intelligibility Rating . . . . . .

Summary . • . . • . . . . . . . 14

III

METHODS AND PROCEDURES . • . . . . . . .

Methods . . . . . . . . . . .

Subjects at Intake

Instrumentation . . . . . . . . .

Subjective Intelligibility

Rating

Developmental Sentence Score 
Procedures . . . . . . . . . . . .

Subgroup Assignments at Age 4

Phonemic Transcription

Phonemic Analysis

Data Analysis

IV

RESULTS AND DISCUSSION • • • • • • • • • •

25

Results ..................... 25

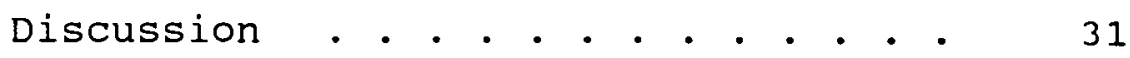

V SUMMARY AND IMPLICATIONS • • • • • . . • 33

Summary • • • • • . • • . • . . . 33

Implications . . . . . . . . . 36

Research

Clinical 


\section{LIST OF TABLES}

TABLE

PAGE

I Summary of Demographic Data of Subjects

at Intake . . . . . . . . . . 16

II Summary of Demographic Data at

Reassessment

III Range, Mean, and standard Deviation of Each Group for PCC Values . . . . . 26

IV ANOVA Results . . . . . . . . . . . 27

V Tukey Test Results . . . . . . . . . . . 


\section{LIST OF FIGURES}

FIGURE

PAGE

1. Chi-Square contingency Table . . . . . . 29

2. Scatter Plot of Spearman Rank Results . . 30 
CHAPTER I

INTRODUCTION AND STATEMENT OF PURPOSE

INTRODUCTION

Highly unintelligible children may mistakenly be assumed to have difficulty only with the misarticulation of consonants. Expressive language concerns may be ignored while the primary focus of intervention becomes the remediation of misarticulated speech. Questions have arisen regarding the possibility of both speech and expressive language difficulties contributing to unintelligibility. The metric percentage consonants correct (PCC) was developed for use in the identification of severity of involvement of phonological disorders.

Nicolosi, Harryman, and Kresheck (1989) define intelligibility as the degree to which verbalizations are understood by the average listener and as being influenced by components such as articulation, rate, fluency, vocal quality, and intensity. Weiss, Gordon, and Lillywhite (1987) define intelligibility simply as understandability.

over the past two decades, the simultaneous occurrence of speech and expressive language delay has been proposed, particularly where highly unintelligible children are concerned. An unintelligible child is often identified as a 
speech client, as misarticulated speech is most often analyzed by speech-language pathologists at the word level on a sound-by-sound basis. Sound-by-sound analysis may leave many articulation errors undetected since this type of assessment consists of elicitation of nonrelated words without any relevant context. Multiple errors of articulation may become apparent only through analysis of continuous speech-language samples. In this case, speech production takes place in a relatively naturalistic setting, content becomes the primary concern rather than merely the articulation of sounds, and a more representative example of the child's speech can be transcribed and analyzed.

Multiple articulation errors may indicate possible phonological involvement as a contributor to unintelligibility. The problem of unintelligibility then becomes one of faulty expressive language development, as phonology is the aspect of linguistics concerned with the sound system of language. Misunderstanding the underlying forms and grammatical components which comprise the sound system of expressive language may result in phonological errors. Manifested as misarticulated speech, these errors indicate more than a simple motoric inability to articulate sounds correctly. Studies have suggested that many children with multiple errors of articulation often have semantic and/or syntactic errors as well (Panagos, 1974; Panagos, Quine, \& Klich, 1979; Paul \& Shriberg, 1982; Schmauch, 
Schmauch, Panagos, \& Klich, 1978; Shriner, Holloway, \& Daniloff, 1969).

Until recently, intelligibility ratings of continuous speech have been primarily subjective in nature. The PCC was developed by Shriberg and Kwiatkowski (1982) as an ordinal means of rating intelligibility and is intended for clinical use. Intelligibility ratings may indicate the need for more specialized methods of remediation, as components of both speech and language may be contributing to unintelligibility.

\section{STATEMENT OF PURPOSE}

The purpose of this study was to compare the PCC produced by three groups of children in order to examine intelligibility and determine if an interrelatedness of speech and expressive language development exists. In addition, this study compared subjective ratings of intelligibility among the three groups; a correlation between the PCC and a subjective rating of intelligibility was also determined. The three groups included children with normal expressive language, children with delayed expressive language, and children with a history of expressive language delay who during the present study demonstrated normal syntactic functioning.

If children with a history of expressive language delay and current syntactic delay were poorer on these measures than normal peers, this would further confirm that 
a speech component does exist in children considered language delayed, and the special needs of these children may then need to be addressed clinically by involving a more global approach to intervention. Further, if quantitative and subjective measures were found to be highly correlated, justification for use of a subjective measure in assessment would be provided. If they did not correlate highly, the need for a quantitative measure of speech accuracy in evaluating children with speech and expressive language disorders would be emphasized.

The specific questions this study proposed were:

1. Is there a significant difference in the PCC produced by children who are normal, expressive language delayed, or have a history of expressive language delay?

2. Is there a significant difference in subjective ratings of intelligibility in these three groups?

3. Does the PCC severity rating correlate significantly with subjective ratings of intelligibility?

These questions lead to the following null hypotheses:

1. There are no significant differences in the PCC produced by normal, expressive language delayed, and history of expressive language delayed children.

2. There are no significant differences in subjective ratings of intelligibility among these groups.

3. There is no significant correlation between the PCC severity ratings and subjective ratings of intelligibility in children in these three groups. 
DEFINITION OF TERMS

For the purpose of this study, the following definitions will be used:

1. History of expressive language delay: Children who at 24-34 months were classified as late talkers and at 4 years of age scored at the loth percentile or higher on the Developmental Sentence Score (DSS) (Lee, 1974).

2. Expressive language delay: Children who at 24-34 months were classified as late talkers and at 4 years of age scored below the loth percentile on the DSS (Lee, 1974).

3. Normal language development: Children who at 24-34 months produced more than 50 words and scored at or above the 10th percentile on the DSS (Lee, 1974).

4. Late talker: Children who produced less than 50 different words at 20-34 months based on a parent report, the Language Development Survey (Rescorla, 1989).

5. Intelligibility: Understandability (Weiss et al., 1987)

6. Percentage consonants correct (PCC): A metric used to identify severity of involvement for phonological disorders (Shriberg \& Kwiatkowski, 1982). 
CHAPTER II

REVIEW OF THE LITERATURE

The branch of linguistics known as phonology involves the study of phonemes and the rules governing their use. Articulation, on the other hand, is the manner in which phonemes are formed to produce speech through the integration of vocal tract movement and positioning of the articulators (Nicolosi et al., 1989). Phonology and articulation both contribute to speech intelligibility.

Assessment practices involving the unintelligible child may prove especially challenging since speech and language disorders have traditionally been conceptualized and treated separately. Multiple errors of articulation, which seriously effect intelligibility, have most often been categorized as speech problems rather than as possible indicators of disordered language. Misarticulated speech is most commonly analyzed at the word level, and unintelligibility may not be reflected as a serious problem when evaluated in this manner. Unintelligible children may be misdiagnosed as speech clients when, in fact, the misarticulated speech may actually be the manifestation of a misunderstanding of the underlying rules which contribute to speech production. Such a misunderstanding may denote a phonological delay. Unintelligibility may also affect the 
clinician's ability to assess language production skills. Unintelligible speech may indicate an isolated articulation disorder, or a more pervasive language deficit with a phonological component, with unintelligibility masking language errors. Assessment of the unintelligible client must accurately reflect the type of difficulty present in order for appropriate remediation to be planned.

\section{NORMAL SPEECH DEVELOPMENT}

Considerable variety exists in early speech sound acquisition although predictable, orderly patterns do emerge as the child's age increases. General trends recognized by Stoel-Gammon and Dunn (1985), Owens (1984), and Weiss, et al. (1987) in phoneme acquisition include:

1. Vowel acquisition occurs prior to consonants.

2. Grouped according to manner, nasals are the first acquired, then glides, plosives, liquids, fricatives, and affricates.

3. Grouped according to place, glottals are the first acquired, then labials, velars, alveolars, dentals, and palatals.

4. Most phonemes, with the exception of fricatives, are mastered first in the initial position, then the final position. Fricatives are acquired in the reverse order, i.e., final position, then initial. 
5. Single consonants are acquired prior to consonant clusters. Some clusters may appear as early as age 2, but the majority are mastered at age 7 or 8 .

Ingram (1976) reviews evidence showing that first syllables are, in order of acquisition, consonant-vowel (CV) or CVCV reduplicated, CVC, CVCV non-reduplicated, and CVCVC. Some initial and final clusters have been added to the child's repertoire by age 2 (Stoel-Gammon \& Dunn, 1985). By age 4 , the child will use a variety of syllable shapes.

In 1987, stoel-Gammon examined the speech samples of 33 2-year-olds to provide speech-language pathologists with a set of norms by which to assess the early phonological development of children. Study findings were similar to those of previous research and correlate well with the consensus of opinion regarding acquisition of phonology as presented by Ingram (1976). A characterization of typical 2-year-old phonology was presented and included: (a) the ability to produce words in $\mathrm{CV}, \mathrm{CVC}, \mathrm{CVCV}$, and CVCVC forms; (b) production of a few consonant clusters in initial position with fewer in final position; (c) production of 9-10 different phones in initial and 5-6 phones in final position; and (d) the ability to match consonant phonemes of adults at $70 \%$ accuracy. In this study, "typical" is considered the average performance of the group, with the norms characterizing what is customarily produced rather than mastery. This study further demonstrated the 
simultaneous correlation between both phonetic and phonologic development and word and syllable development.

Although intelligibility is less predictable in development than articulation, for most children continuous speech is $100 \%$ intelligible by age 4 (Weiss, et al., 1987). It is, however, considered normal for children up until 4 years of age to use a variety of phonological processes when attempting to produce adult word forms. These processes are strategies which simplify production of the target, making it easier to produce. In delayed speech development, phonological processes persist after the age of 4 years.

INTERACTIONS BETWEEN SPEECH AND LANGUAGE DEVELOPMENT IN LANGUAGE DISORDERED CHILDREN

Children with severely misarticulated speech were identified, in a 1974 study by Panagos, as actually simplifying syllable complexity. This simplification was identified as being merely one symptom of a more universal language disorder and phonologic in nature. Panagos (1974) suggests that as an aspect of language, sound system deviations should be remediated using a broader linguistic approach rather than using the traditional sound-by-sound approach. He further states that by adding a syntactic aspect to intervention, dramatic improvements were made. It is this improvement which gives credence to the hypothesis that serious defects in articulation may actually indicate an overall language disorder as the findings of this study 
claim. As such, misarticulated speech enters the realm of language. This implies that a deeper cognitive root may be responsible for the limitations in knowledge and rule use of poor speech and unintelligibility manifested as phonological productions.

Further relationships between misarticulated speech and language have been evidenced in a study by shriner et al. (1969). Comparisons of the complexity of syntactic structures of children were made with normal and defective articulation. The children with defective speech were found to use simpler, shorter sentences than those with normal speech patterns. Several reasons for this syntactic difference were hypothesized. One reason given was that children with defective articulation are aware of their defective speech, making them disinclined to speak. A second reason given for the difference in syntax is that children with defective articulation have less opportunity to try new and more complex syntactic structures, because they speak less often.

In a small study by Menyuk (1964), the grammar of children using "infantile speech" was compared to the grammar of children using normal speech. This study, which was based on a generative model of grammar, found that children with normal speech used more transformations than children with "infantile speech." The children with the deviant speech patterns used more restricted forms and simplified rules syntactically. In addition, in a sentence 
repetition task, omissions were frequent in longer sentences and repetition of only the last words of sentences was typical. This was not the case with the children using normal speech.

Consonants occurring in phonologically complex words and syntactically complex structures were produced with less accuracy by 17 children with functional articulation problems than children without articulation problems in a study by Panagos, et al. (1979). The 17 phonologically delayed children studied had not yet mastered the later developing sounds $|\theta|,|f|,|g|$, and $|d z|$ as had their normally developing peers. When these consonants were used within a complicated syntactic structure, the phonologically delayed children were less accurate in their articulation than they would have been had each word been produced in isolation. This simplification is attributed to limitations in processing and organizational skills which contribute to evidence of the "relationships between syntactic and phonological deficits" (p. 846).

In more recent research, Paul and Shriberg (1982) studied the phonological and syntactical interactions of children with delayed phonological production. Thirty children were classified into one of four proposed pattern types. Pattern I children manifest both phonological and syntactical deficits. Pattern II types use age-appropriate syntactic skills, but delayed use of morphophonemes at or below their age-appropriate syntactic level. Pattern III 
types are delayed syntactically, but use age-appropriate morphology. Pattern IV types produce age-appropriate syntax and morphology. Findings were similar, in part, to previous studies relating speech disordered children's difficulty with sentence complexity. The performance of children classified as Pattern I or Pattern II could be attributed to a limited encoding capacity, defined in the study as the underlying inability to organize language in a hierarchical manner. This was not the case with children classified as Pattern III or Pattern IV. The authors concluded from study results that although some speech disordered children could be characterized as having a limited encoding capacity, this was not true in all cases. Some children appeared to be able to produce appropriate articulation when underlying grammatical forms demanded it, indicating a relationship between speech and language abilities.

Shriberg and Kwiatkowski (1988) report in a follow-up of a 1986 study that the term phonologic disorder is an appropriate term to use when classifying the majority of children with speech disorders of unknown origin. The study proposed that children with phonologic disorders, unlike children with articulation errors only, require longer term intervention in order to overcome their speech-language deficits. Further, the results of this study indicate that children with early language problems, including phonological disorders which affect intelligibility, will continue to have problems in areas other than simply 
language and may benefit from special educational services. This study further reports that Tyler and Edwards (1986) found severity of speech involvement as measured by PCC did not associate with a continued need for speech-language services into the school years, while poor intelligibility ratings did indicate such a need. Shriberg and Kwiatkowski (1988) found that a low correlation between PCC and intelligibility ratings has been shown in studies by Bishop and Edmundson (1987), Shriberg (1986), and Shriberg and Kwiatkowski (1982).

\section{INTELLIGIBILITY RATING}

PCC, a metric used to assess the constructs of disability, intelligibility, and handicap, was developed by Shriberg and Kwiatkowski (1982). This metric was created for use by speech-language pathologists and researchers to assist in the diagnosis and management of those individuals with developmental phonological disorders. Adjectives describing the severity of involvement, including "mild," "mild-moderate," "moderate-severe," and "severe," are generated from PCC values calculated through analysis of speech-language samples. However, time constraints have traditionally necessitated that clinicians assign subjective ratings of intelligibility at the time of evaluation rather than determining PCC values. 
SUMMARY

Most studies which have pursued the possibility of co-existing speech and language delays, appear to indicate that a relationship does exist between the two, that is, children who manifest difficulties through multiple misarticulations of speech often have difficulty with the underlying structures of language as well. If a co-occurrence of speech and language involvement does exist, there appears to be a genuine need for a diagnostic tool which will identify those individuals and enable the speech-language pathologist to plan the most effective method of remediation. The PCC rating may be found to be an effective means of identifying those highly unintelligible children who have a greater severity of involvement in both speech and language. Degree of intelligibility may be a key factor in the diagnosis of speech and language involvement. If severity of involvement and unintelligibility are found to correlate, then a subjective means of evaluating intelligibility which is accurate, accountable, and has a positive correlation to PCC values would benefit clinicians and researchers alike. 
CHAPTER III

METHODS AND PROCEDURES

METHODS

\section{Subjects at Intake}

Forty-two children between 48 and 59 months old were included as subjects in this study. These children had been a part of the Portland Language Development Project, a longitudinal research study of language development at Portland State University, Portland, Oregon. Subjects between the ages of 20 and 34 months were recruited from local pediatric clinics through an article placed in a local newspaper or through a local radio broadcast. All subjects included in the study passed a hearing screening as well as an informal screening which confirmed that there were no neurological or physical handicaps at age 2 . Subjects participating in the study had a standard score of 85 or above on a test verifying intellectual functioning at age 2either the Bayley Scale of Infant Development (Bayley, 1969) or the Stanford-Binet Intelligence Scale (Terman \& Merrill, 1960). Table I presents demographic data of the subjects at intake.

Subjects were divided into two groups based on results of a parent report using the Language Development Survey 


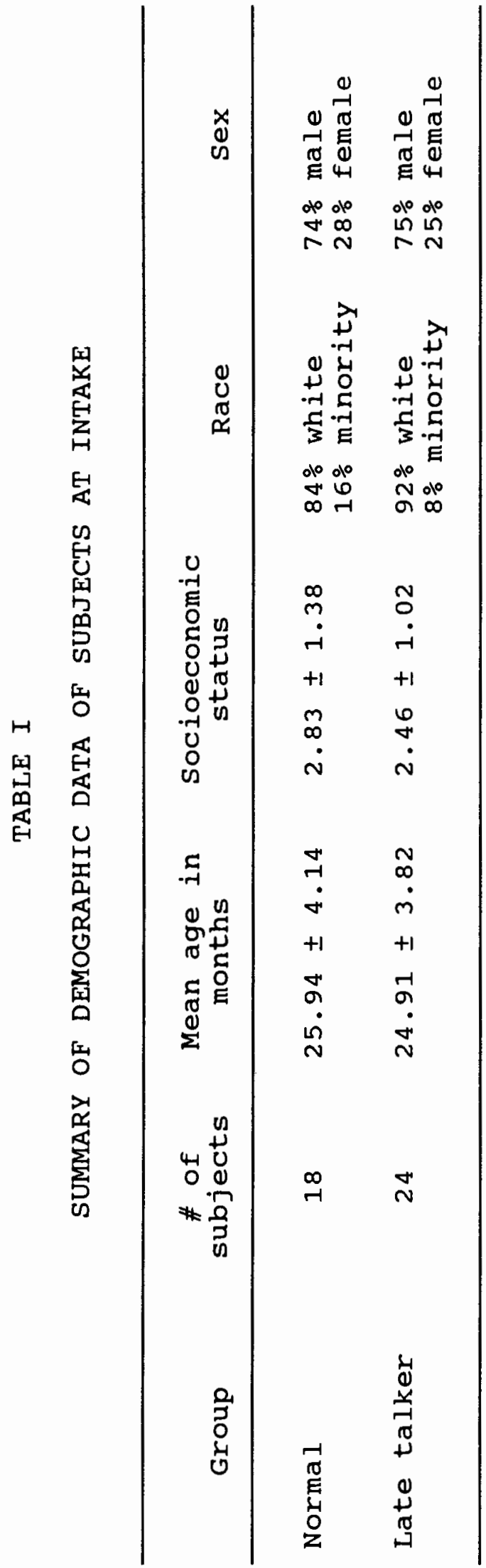


(LDS) developed by Rescorla in 1989. The LDS is a checklist of 300 common words found in children's early vocabulary. The LDS has been shown to have excellent reliability, validity, sensitivity, and specificity for differentiating between 2-year-olds with normal language development and those with expressive language delays. Children were placed in the normal group if they produced more than 50 words at 20-34 months. Children were placed in the late talker group if they produced less than 50 different words at 20-34 months.

Subjects were seen at a follow-up assessment between their fourth and fifth birthday. At this time, the mean age of the normal group was 50 months with a standard deviation of 2.72 and a range of 49-57 months. The mean age of the late talker group was 51 months with a standard deviation of 2.31 and a range of 48-57 months. The Test of Language Development-Primary (TOLD-P) (Newcomer \& Hammill, 1982) was administered, and receptive language was found to be within normal limits. A speech-language sample was gathered via audiotape for this sample. Each subject was audiotaped in a clinic room at Portland State University with an audio cassette recorder operated by a graduate student. Parents were instructed to play with their children as they would at home. An assortment of toys was made available for each parent and child to play with while they were being taped. Taping time was 10 to 15 minutes. A Sony BM-80 Dictator/Transcriber was used to record the parent-child 
interaction in conjunction with a Sony ECM-D8 electret condenser microphone. The mother-child interaction was recorded and transcribed by hand according to Miller's (1981) procedures. A DSS (Lee, 1974) was determined for each subject. In addition, each subject was given a subjective intelligibility rating of good, fair, or poor at the time of the evaluation by a graduate research assistant in speech-language pathology.

\section{INSTRUMENTATION}

\section{Subjective Intelligibility Rating}

Subjective intelligibility ratings were determined by graduate research assistants in speech-language pathology who were present at the taping of the mother-child interactions gathered for speech samples. An adjective"good", "fair", or "poor"-was chosen to rate the child's overall intelligibility at the time of the recording. If the research assistant believed more than $90 \%$ of what the child said was understood, a rating of good was selected; a rating of fair was selected if between $70 \%$ and $90 \%$ was understood; and a rating of poor was selected if less than $70 \%$ was understood.

\section{Developmental sentence score}

The DSS was developed by Lee (1974) to analyze expressive syntax in spontaneous speech-language samples. The DSS is one of a few standardized methods available for 
analyzing speech-language samples. Norms were established for children ages 1 year/6 months to 8 years of age. A DSS score can identify whether a child is significantly different from normal. If a score is below the tenth percentile, a child's expressive language is considered delayed. Fifty complete sentences are used in the analysis. A complete sentence is recognized as one which contains both subject and predicate. The DSS analyzes eight areas of syntax, including indefinite pronouns, personal pronouns, main verbs, secondary verbs, negatives, conjunctions, interrogative reversals, and wH-questions (i.e., who, what, where, when and why). Points are awarded for each correctly used area and a higher score is given for use of a more complex form. A sentence point is awarded if the entire sentence is grammatically correct. Total points earned divided by the number of utterances scored yields the developmental sentence score. Lee (1974) reports good construct validity and inter-judge and intra-judge reliability.

\section{PROCEDURES}

Subgroup Assignments at Age 4

The children seen at age 4 were divided into three subgroups, based on their DSS score. The normal subgroup consisted of children originally diagnosed as normal and who have continued to show normal language development as indexed by scores above the loth percentile on the DSS. A 
second diagnostic group consisted of children who at intake were considered late talkers, but had since developed normal language skills as evidenced by performance above the 10th percentile on the DSS. This group is referred to as the history of expressive language delay group. The third diagnostic group consisted of children who were diagnosed as late talkers at intake and continued to score below the 10th percentile on the DSS at the 4-year-old follow-up. This group is designated expressive language delayed. The mean age in months of the normal group was $50.72 \pm 2.78$. The mean age in months of the history of expressive language delay group is $50.54 \pm 2.33$. The mean age of the expressive language delay group in months is 50.90 \pm 2.38 . Table II presents demographic data on these three subgroups at the time of reassessment.

A one-way analysis of variance (ANOVA) indicated no significant difference among the three groups on age and socioeconomic status. An alpha level of .05 was used to determine statistical significance.

\section{Phonemic Transcription}

A Sony BM-80 Dictator/Transcriber and a Zenith Data Systems computer and monitor were used to transcribe phonemically the speech-language samples for which the DSS had been previously computed. Broad transcription was used. The Programs to Examine Phonetic and Phonologic Evaluation 


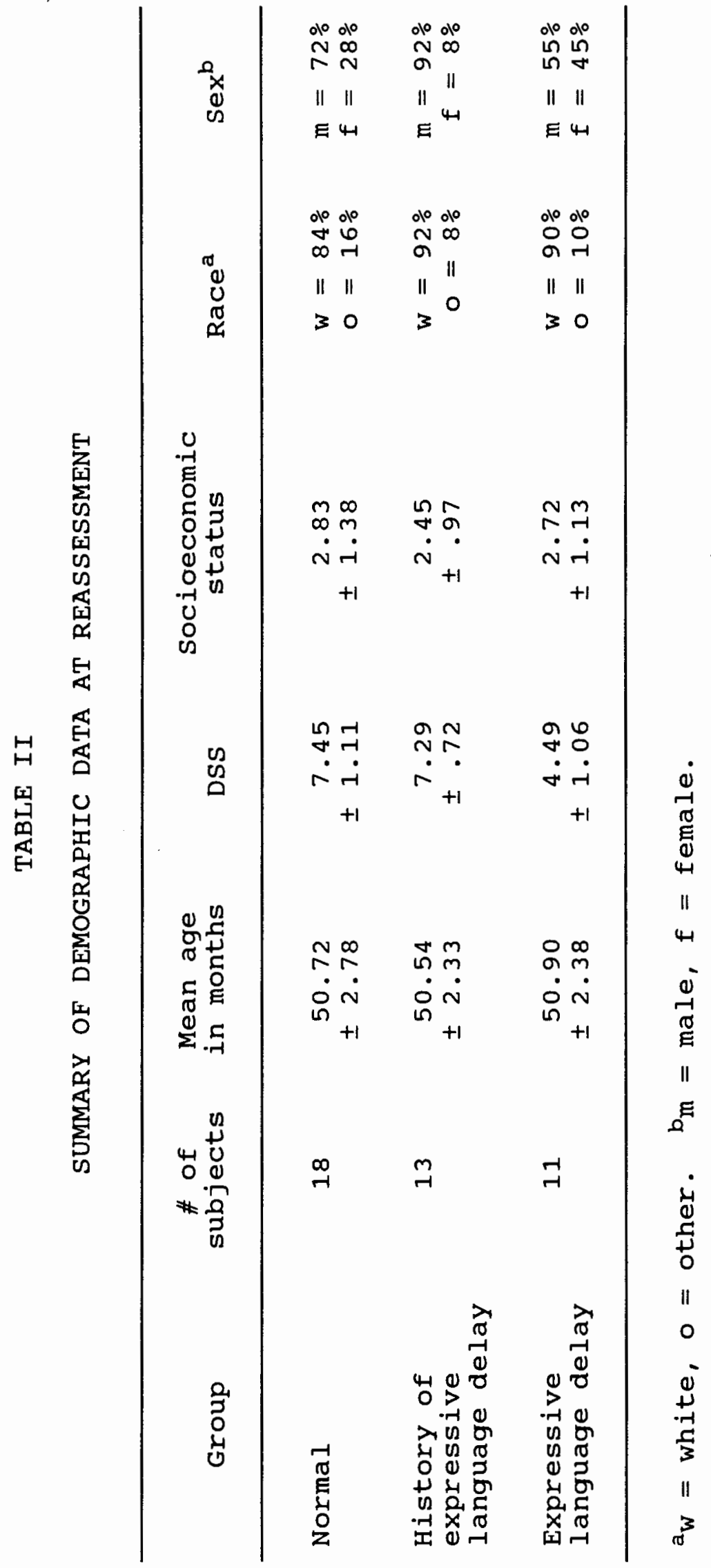


Records (PEPPER), a computer program developed by Shriberg in 1986, calculated the PCC for each sample.

Phonemic transcriptions of the audiotapes consisted of at least 90 nonquestionable, different words for each subject. The PEPPER transcription format consists of three lines, $X, Y$, and $Z$, for each utterance included in the analysis. The $\mathrm{X}$ line is for orthographic representations, the $Y$ line for intended phonemic output, and the $\mathrm{Z}$ line for actual phonemic output.

\section{Phonemic Analysis}

The computer software program PEPPER was used to analyze each subject's speech-language sample. The program was designed to evaluate the phonemic transcription of continuous speech-language samples. This was accomplished by the PEPPER in the present study.

Shriberg and Kwiatkowski (1982) developed a "severity of involvement" construct, the PCC, and as a result of a listener rating study, substantiated its reliability and validity. In the PCC validation study, 52 speech-language pathologists listened to tapes of speech samples and rated severity of involvement of 32 children with delayed speech. The PCC was identified as the best predictor of severity rating.

The PCC analysis consists of sound-by-sound comparisons of the consonants in the $\mathrm{Y}$ and $\mathrm{Z}$ lines. Each 
consonant entered identically in the $\mathrm{Y}$ and $\mathrm{Z}$ line is considered correct.

The PEPPER program establishes a numeric value which is converted to a severity of involvement adjective. If PCCs are between $85-100 \%$, the adjective assigned is "mild"; between 65-85\%, "mild-moderate"; between 50-65\%, "moderate-severe"; and less than 50\%, "severe." Output also includes an Intelligibility Index as part of the word coding Summary. The Intelligibility Index is based on the percentage of intelligible words with "disregards" removed from computation. Disregards are considered fillers, false starts, and repeated words.

Approximately $10 \%$ of the speech-language samples were phonemically transcribed using broad transcription by another graduate student in speech-language pathology. Transcription was done independently, as was input into the PEPPER computer program, to insure inter-rater reliability. A point-to-point reliability system was used. A segment of the transcribed utterances of each speech-language sample was extracted and each transcriber's input compared to the input of the other transcriber in order to insure at least $90 \%$ agreement. Agreement was established at $97 \%$.

\section{Data Analysis}

An ANOVA was used to detect and explore the differences among the three groups. In the present instance, the PCC served as the dependent variable of 
interest. In the event of a significant result, a post-hoc multiple comparison (Tukey's Honestly significant Difference) was planned. In addition, a chi-square analysis was used to determine the extent of association between group membership and the subjective ratings of intelligibility. Finally, the relationship between the PCC severity rating and the subjective intelligibility rating was explored. In this case, a Spearman Rank order correlation coefficient was computed. 
CHAPTER IV

\section{RESULTS AND DISCUSSION}

\section{RESULTS}

The purpose of the study was to compare the PCC and intelligibility ratings of three groups of children to determine if an interrelatedness between speech and expressive language delay exists. The means, standard deviations, and ranges for the dependent measure were computed and are shown in Table III. The data were analyzed to determine whether significant differences for PCC values existed among the three groups-children with normal language, history of expressive language delay, and language delay.

The study addressed three specific questions. The first question asked was: Is there a significant difference in the PCC produced by children are normal, expressive language delayed, or who have a history of expressive language delay? An ANOVA was used to detect differences between group means of PCC values (see Table IV).

Results displayed in Table $\mathrm{V}$ reveal a significant difference ( $\underline{p}<.05)$ among the groups. A Tukey test found that the normal group received significantly better PCC values than both the expressive language delayed and the 
TABLE III

RANGE, MEAN, AND STANDARD DEVIATION

OF EACH GROUP FOR PCC VALUES

Measure Group ${ }^{a} \underline{n}$ Minimum Maximum Mean $\underline{\text { SD }}$

$\begin{array}{lcccccc}\text { PCC } & 18 & 86.04 & 99.64 & 94.95 & 4.64 \\ \text { History } & 13 & 73.72 & 95.85 & 88.68 & 6.89 \\ \text { Delay } & 11 & 81.53 & 98.96 & 88.43 & 4.71\end{array}$

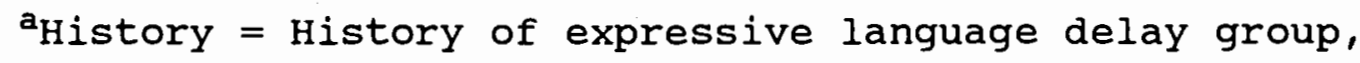
Delay = Expressive language delay group.

history of expressive language delayed group. No significant difference was found between the PCC values of the delayed group and the history of delay group. Results indicate that children with delayed expressive language or a history of delayed expressive language produce a significantly lower PCC than children with normal language. The second question asked was: Is there a significant difference in subjective ratings of intelligibility among the three groups? A chi-square analysis was conducted to establish the extent of association between subjective ratings of intelligibility and the various language groups. since the groups were not sufficiently large to justify a chi-square analysis in a 3 X 3 table, the "poor" and "fair" 
TABLE IV

ANOVA RESULTS

\begin{tabular}{lcccc}
\hline Source & $\begin{array}{c}\text { Sum of } \\
\text { squares }\end{array}$ & $\begin{array}{c}\text { Degrees of } \\
\text { freedom }\end{array}$ & $\begin{array}{c}\text { Mean } \\
\text { square }\end{array}$ & $\underline{F}$ \\
\hline Between & 420.30 & $3-1=2$ & 210.52 & \\
Within & $\underline{1161.037}$ & $\underline{42-3=39}$ & 29.77 & \\
Total & 1581.337 & $42-1-41$ & & 7.0591 \\
\hline
\end{tabular}

subjectively rated intelligibility groups were combined. The contingency table is displayed in Figure 1.

A significant difference $(\underline{\underline{ }}<.05)$ was found between the group rated "good" on intelligibility and the combined groups rated "fair" and "poor" on intelligibility. The resultant $\chi^{2}$ was 15.8 with 2 degrees of freedom. This chi-square yields a contingency coefficient of .522 . Eighty-nine percent of the subjects in the normal language group were associated with "good" subjective ratings, while $82 \%$ of the delayed expressive language group was associated with the "fair" and "poor" subjective ratings. The history of expressive language delay group was split almost evenly between the combined "fair" and "poor" group and the "good" group. These results substantiate the expectation that the intelligibility in the normal group would more likely be 


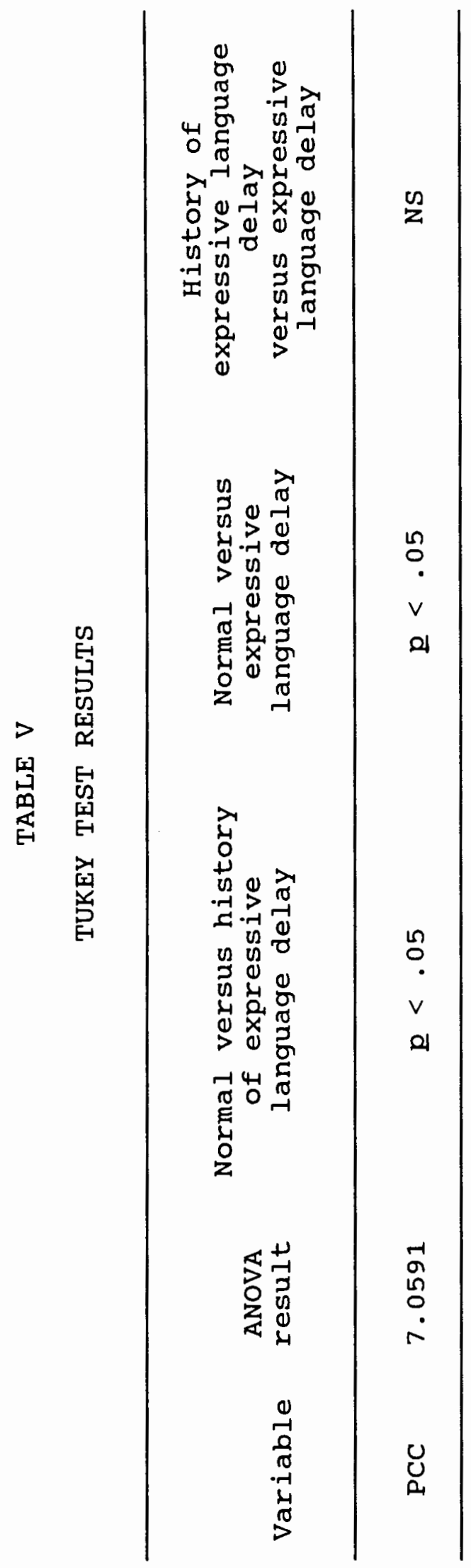




$\begin{array}{ccc}\text { Delayed } & \text { History of } & \text { Normal } \\ \text { expressive } & \begin{array}{c}\text { expressive } \\ \text { language } \\ \text { delage }\end{array} & \end{array}$

\begin{tabular}{|c|c|c|c|}
\hline Fair/Poor & $\begin{array}{c}82 \% \\
(\underline{\mathrm{n}}=9)\end{array}$ & $\begin{array}{c}62 \% \\
\left(\underline{n}^{=}=8\right)\end{array}$ & $\left(\underline{n}^{11 \%}=2\right)$ \\
\hline Good & $\begin{array}{c}18 \% \\
(\underline{n}=2)\end{array}$ & $\begin{array}{c}38 \% \\
(\underline{\mathrm{n}}=5)\end{array}$ & $\begin{array}{c}89 \% \\
(\underline{\mathrm{n}}=16)\end{array}$ \\
\hline & $\begin{array}{c}100 \% \\
(\underline{n}=11)\end{array}$ & $\begin{array}{c}100 \% \\
(\underline{n}=13)\end{array}$ & $\left(\underline{\mathrm{n}} \begin{array}{c}100 \% \\
=\end{array}\right.$ \\
\hline
\end{tabular}

Figure 1. Chi-square contingency table.

rated "good", the expressive language delay group would more likely be rated "fair" or "poor", and the history of expressive language delay group would be roughly equivalent across the two rating groups.

The third question asked was: Does the PCC severity rating correlate with subjective ratings of intelligibility? A Spearman Rank correlation coefficient was used to determine the relationship between the PCC severity rating and subjective ratings of intelligibility. The spearman Rank correlation coefficient yielded a rho of .504 at the .05 level of significance $(\underline{\mathrm{df}}=40)$. This indicates that subjective judgements of establishing intelligibility correlate moderately well with computer-generated PCC severity ratings. Figure 2 shows the distribution. 


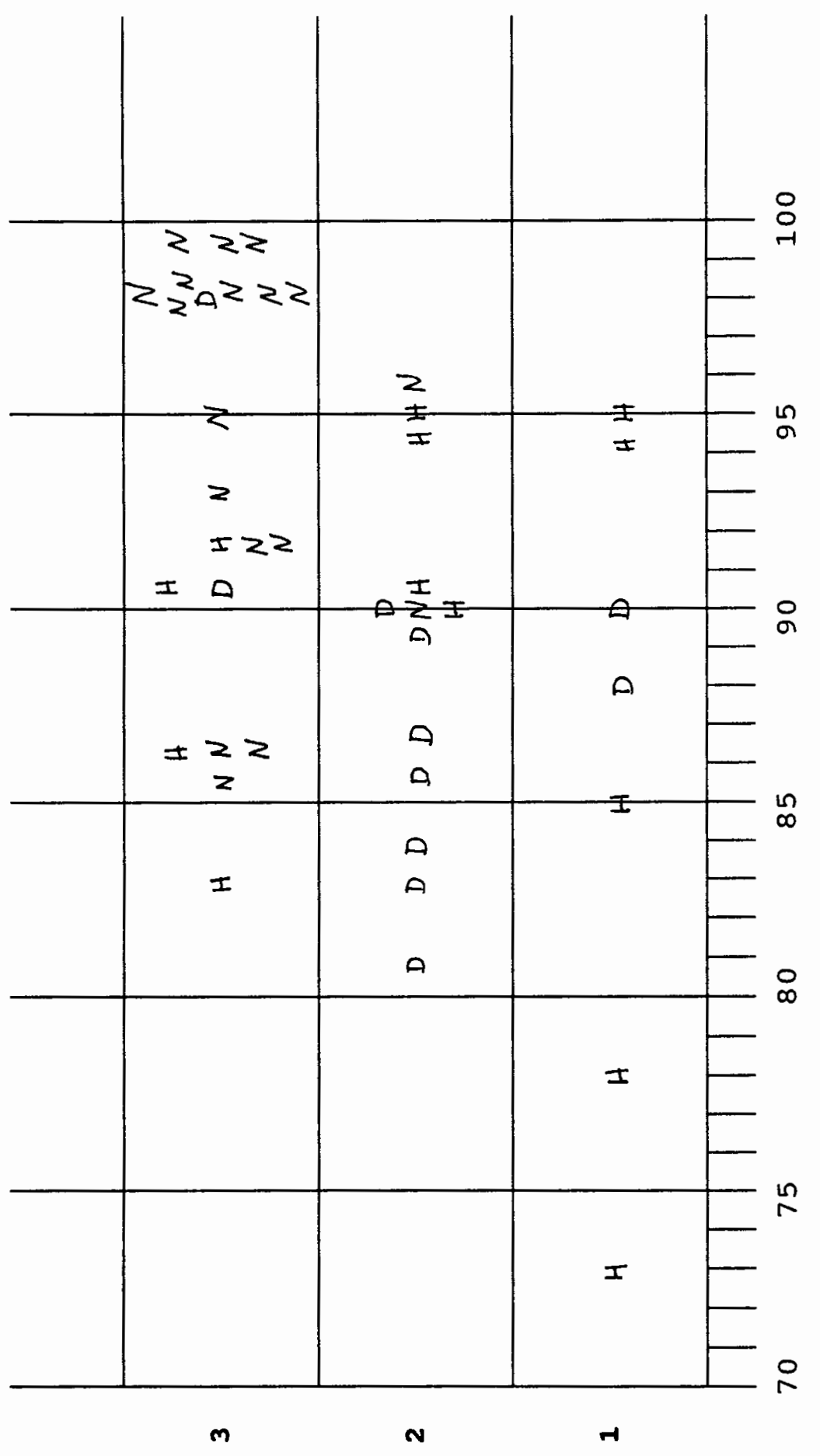

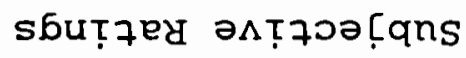

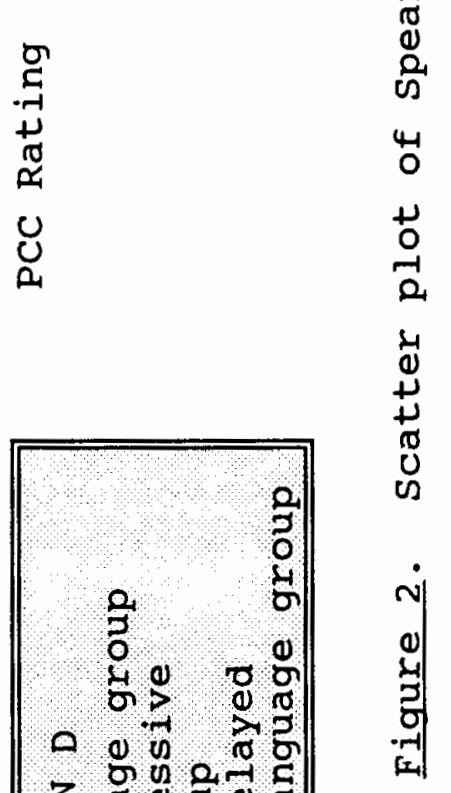

告

站

톨

㟧

苍

4
0
+1
0
0
0
0
4
3
-4
-4

, 130301

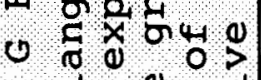

त 1 , 0 , -10 d 0

$0>\geq 0$ $\mathrm{H}=\mathrm{g}$ o $00-1 x$ ZAमI 0

II II II

$\mathrm{Z} \mathrm{O} I$ 


\section{DISCUSSION}

The results of the first question posed by this investigation revealed that children with expressive language delay or a history of expressive language delay do indeed produce a lower PCC than children with normal expressive language skills. While no significant differences were found between the history of expressive language delay and expressive language delay group, a significant difference was detected between the normal and history of expressive language delay group and the normal and expressive language delayed group. This may be evidence to support the interrelatedness of speech intelligibility and language development. Of particular interest is the finding that children in the history of expressive language delay group at age 4 years fell within the normal range syntactically, but intelligibility remained significantly below that of the children of the normal group. The usefulness of the PCC as a component in the determination of severity of involvement could be suggested.

This study found significant differences in subjective ratings of intelligibility among the three groups of children-normal, history of expressive language delayed, and expressive language delayed. This suggests that speech-language pathologists are able to identify differences in understandability of speech based on listening skills and in a manner that relates moderately 
well to the quantitative PCC. This finding alleviates the need for use of a quantitative method of assessment of intelligibility such as the PCC which, although useful, is not practical for most clinically or school-based speech-language pathologists who are faced with strict time constraints in the diagnosis of clients. It appears that subjective ratings of intelligibility are reasonably accurate when compared to objective methods such as the PCC. The fact that the differences among groups were significant indicates that the subjective method of diagnosing intelligibility is as sensitive to these group differences as the objective method of comparing PCCs is.

The present study found a moderate, yet significant correlation between subjective ratings of intelligibility and quantitative PCC ratings. PCC ratings appear to be a reliable indication of severity of involvement (Shriberg \& Kwiatkowski, 1982), and results of this study indicate that subjective ratings of intelligibility establish differences in understandability in children as well. This information suggests that speech-language pathologists should thoroughly assess highly unintelligible children in both articulation and expressive language prior to proposing a treatment plan. It is possible that severity of involvement is at more than the articulatory level manifested by misarticulated speech. 


\section{CHAPTER V \\ SUMMARY AND IMPLICATIONS}

\section{SUMMARY}

Highly unintelligible children may mistakenly be assumed to have difficulty with only the misarticulation of consonants. Expressive language concerns may be ignored while the primary focus of intervention becomes the correction of misarticulated speech. Questions have arisen regarding the possibility of both speech and expressive language difficulties contributing to unintelligibility. In 1982, Shriberg and Kwiatkowski developed an ordinal means of rating severity of involvement. One of the constructs of their severity scale was intelligibility. The metric PCC was developed to be used to identify severity of involvement of disorders of phonology.

The purpose of the present study was to compare PCC produced by three groups of children in order to examine intelligibility and determine a possible interrelatedness of speech and expressive language development. Children taking part in a longitudinal study were placed into one of two groups based on results of a parent report using the Language Development Survey (Rescorla, 1989). The survey was given when the children were 2 years of age. Those 
children placed in the group labeled "normal" produced more than 50 words at 20-34 months. Children placed in a group labeled "late-talkers" produced less than 50 words at 20-34 months. At a follow-up assessment at 4 years of age, the children were divided into three groups based on scores received on a spontaneous speech-language sample assessed using Lee's (1974) DSS. The normal subgroup was redefined to consist of children diagnosed as normal at intake and whose scores on the DSS at 4 years of age were at or above the 10th percentile. A second group consisted of children considered late-talkers at intake and whose scores were above the 10th percentile on the DSS at 4 years of age. This group was referred to as the history of expressive language delay group. A third group consisted of children considered late-talkers at intake and whose scores were below the 10th percentile on the DSS at 4 years of age. This group was referred to as the expressive language delayed group.

Speech-language samples from the 4-year evaluation were phonetically transcribed and entered into a computer. PEPPER software, developed by Shriberg (1986), analyzed the input. A PCC value was determined for each language sample.

The following specific questions were addressed:

1. Is there a significant difference in the PCC produced by children who have normal expressive language, are expressive language delayed, or have a history of expressive language delay? 
2. Is there a significant difference in subjective ratings of intelligibility among these three groups?

3. Does the PCC severity rating correlate with subjective ratings of intelligibility?

The data were analyzed to determine if significant differences existed on the PCC values produced by the language diagnostic groups. An ANOVA test found a significant difference $(\underline{F}=7.06$ at the .05 level of significance). A Tukey test found that the normal group received significantly better PCC values than both the history of expressive language delay group and the expressive language delay group. No significant difference was found between the PCC values of the expressive language delay group and the history of expressive language delay group.

A chi-square analysis was conducted to establish the extent of the association between subjective ratings of intelligibility and the three groups. A strong significant difference was found between the group rating "good" on intelligibility and the combined groups rating "fair" and "poor" on intelligibility. The normal expressive language group was most often associated with "good" subjective ratings of intelligibility while the delayed expressive language group was most often associated with the "fair" and "poor" subjective ratings of intelligibility. The history of expressive language delay group rating was split between 
the two subjective ratings, the combined "fair" and "poor" group and the "good" group.

A Spearman Rank correlation coefficient was performed to determine the relationship between PCC severity rating and subjective ratings of intelligibility. A moderate yet significant difference $(\underline{p}<.05)$ was found.

\section{IMPLICATIONS}

\section{$\underline{\text { Research }}$}

Future research of interest would include a similar study with larger group sizes in order to better track differences between the history of delay group and the expressive language delay group. It would also be interesting to follow groups of unintelligible children undergoing different methods of intervention: those receiving speech remediation in a traditional manner, correction of separate consonants only versus those receiving phonological intervention, targeting groups of phonemes as well as some type of expressive language remediation. Would the children receiving both speech and language remediation make greater strides in improving intelligibility than those receiving only articulation therapy?

A comparison of subjective ratings of intelligibility in speech-language samples in which all unintelligible utterances and words were included would be a study of further interest. The PCC analysis disregards totally 
unintelligible words; consequently, no comparison of consonants in these words is possible. Inclusion of whole word unintelligibles would provide more information as to the type of phonological patterns being produced as well as aiding in the development of remediation goals. In addition, subjective ratings of intelligibility might be more accurately evaluated if based on a finer rating scale, one providing more increments such as "poor," "poor-fair," "fair," "fair-good," and "good."

\section{Clinical}

These data suggest that an interrelatedness of speech and language delay may exist. If a high degree of unintelligibility does reflect expressive language difficulties, great care must be taken by the speech-language pathologist in diagnosing and planning remediation for this type of client. Perhaps the study finding of greatest interest is that the history of expressive language delay group remains significantly less intelligible than the normal group. At intake (2 years old) the history of expressive language delay group was identified as having poor semantic skills, and at age 4 years syntactic language skills had "caught up" with syntactic language skills of the normal language group. It would be interesting to follow the less intelligible history of expressive language delay group. Would their language would continue to fall within the normal range or would they 
once again fall behind as they mature and their language use is expected to become more complex? Although

speech-language pathologists may be correctly identifying intelligibility skills, as the present study suggests, careful assessment in areas of both speech and language of children with poor intelligibility should occur and perhaps should continue throughout the school years. It may be further suggested that because of the apparent language component to unintelligibility, a phonological approach would prove to be the most successful method of remediation. since PCC ratings appear to be a good indication of severity of involvement and findings indicate a moderate correlation with subjective ratings of intelligibility, then speech-language pathologists can feel confident in their subjective assessments and use assessment information when diagnosing and establishing a mode of treatment for the unintelligible client. In other words, more than articulatory considerations should be included in cases of highly unintelligible children. Language issues must also be included in the remediation plan. Testing a child who is highly unintelligible for language deficits is challenging when it is difficult to understand what is being said by the child, and the first inclination of the examiner might be to address misarticulations. However, language issues should not be ignored.

PCC analysis remains an unlikely choice for clinicians working under strict time constraints. In addition to 
lengthy transcription and entry considerations, the PCC does not include totally unintelligible words in its analysis. In addition, although these words are not understandable, they could add further insight into types of error patterns specific clients make. 
REFERENCES

Bayley, N. (1969). Bayley scales of infant development. New York: Psychological Corporation.

Bishop, D., \& Edmundson, A. (1987). Language-impaired 4-year-olds: Distinguishing transient from persistent impairment. Journal of Speech and Hearing Disorders, 52, 156-173.

Ingram, D. (1976). Phonological disability in children. New York: Elsevier.

Lee, L. (1974). Developmental sentence analysis. Evanston, IL: Northwestern University Press.

Menyuk, P. (1964). Comparison of grammar of children with functionally deviant and normal speech. Journal of Speech and Hearing Research, 7, 109-121.

Miller, J. F. (1981). Assessing language production in children: Experimental procedures. Baltimore: University Park Press.

Newcomer, P. , \& Hammill, D. (1982). Test of language development. Austin, TX: Pro-Ed.

Nicolosi, L., Harryman, E., \& Kresheck, J. (1989). Terminology of Communication Disorders ( $3 r d$ ed.). Baltimore, MD: Williams \& Wilkins.

Owens, R. (1984). Language Development: An introduction (2nd ed.). Columbus, $\mathrm{OH}$ : Merrill Publishing Company.

Panagos, J. (1974). Persistence of the open syllable reinterpreted as a symptom of language disorder. Journal of Speech and Hearing Disorders, 39, 23-31.

Panagos, J., Quine, M., \& Klich, R. (1979). Syntactic and phonological influences on children's articulation. Journal of Speech and Hearing Research, 22, 841-848.

Paul, R., \& Shriberg, L. (1982). Associations between phonology and syntax in speech-delayed children. Journal of Speech and Hearing Research, 25, 536-547. 
Rescorla, L. (1989). The language development survey: A screening tool for delayed language in toddlers. Journal of Speech and Hearing Disorders, 54, 587-599.

Schmauch, V., Panagos, J., \& Klich, R. (1978). Syntax influences the accuracy of consonant production in language-disordered children. Journal of Communication Disorders, 11, 315-323.

Shriberg, L. (1986). Programs to examine phonetic and phonologic evaluation records (PEPPER). Madison, WI: University of Wisconsin Board of Regents.

Shriberg, L., \& Kwiatkowski, J. (1982). Phonological disorders III: A procedure for assessing the severity of involvement. Journal of Speech and Hearing Disorders, 47, 256-270.

Shriberg, L., \& Kwiatkowski, J. (1988). A follow-up study of children with phonologic disorders of unknown origin. Journal of Speech and Hearing Disorders, 53, $144-155$.

Shriner, T., Holloway, M., \& Daniloff, R. (1969). The relationship between articulatory deficits and syntax in speech defective children. Journal of Speech and Hearing Research, 12, 319-325.

Stoel-Gammon, C. (1987). Phonological skills of 2-year-olds. Lanquage, Speech, and Hearing Services in Schools, 18, 312-322.

Stoel-Gammon, C., \& Dunn, C. (1985). Normal and disordered phonology in children. Baltimore: University Park Press.

Terman, L., \& Merrill, M. (1960). Stanford-Binet intelligence scale. Boston: Houghton Mifflin.

Tyler, A., \& Edwards, M. L. (1986, November). phonologically disordered preschoolers: At risk for later learning problems? Paper presented at the Annual Convention of the American Speech-Language-Hearing Association, Detroit.

Weiss, C., Gordon, M. , \& Lillywhite, H. (1987). Clinical management of articulatory and phonologic disorders (2nd ed.). Baltimore, MD: Williams \& Wilkins. 


\begin{abstract}
APPENDIX
PERCENTAGE CONSONANT CORRECT (PCC)

SAMPLE OF OUTPUT
\end{abstract}

Source: Shriberg, L. (1986). Programs to examine phonetic and phonologic evaluation records (PEPPER). Madison, WI: University of Wisconsin Board of Regents. 
FEFICEHTAGE COHSONANTS COFIFECT (FTC)

SEF' 12, 'BG

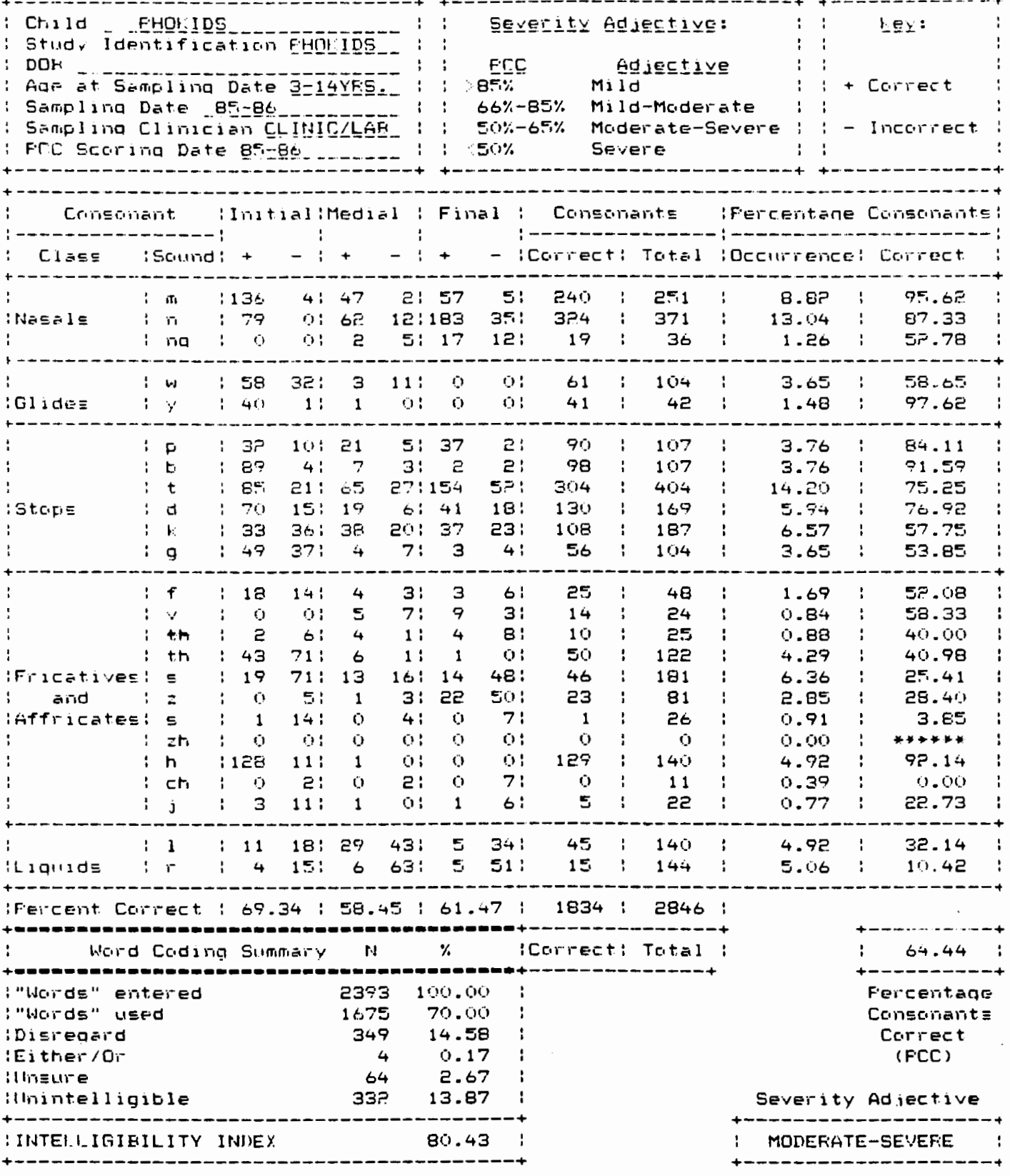

